Review

\title{
Gold Nanoparticle-Biological Molecule Interactions and Catalysis
}

\section{Jonathan G. Heddle}

Heddle Initiative Research Unit, RIKEN, 2-1 Hirosawa, Wako, Saitama, 351-0198, Japan; E-Mail: heddle@riken.jp; Tel.: +81-48-367-4598; Fax: +81-48-462-4701

Received: 18 May 2013; in revised form: 1 August 2013 / Accepted: 12 August 2013 /

Published: 3 September 2013

\begin{abstract}
This review gives a brief summary of the field of gold nanoparticle interactions with biological molecules, particularly those with possible catalytic relevance. Gold nanoparticles are well known as catalysts in organic chemistry but much is unknown regarding their potential as catalysts of reactions involving biological molecules such as protein and nucleic acids. Biological molecules may be the substrate for catalysis or, if they are the ligand coating the gold particle, may be the catalyst itself. In other cases biological molecules may form a template upon which gold nanoparticles can be precisely arrayed. As relatively little is currently known about the catalytic capabilities of gold nanoparticles in this area, this review will consider templating in general (including, but not restricted to, those which result in structures having potential as catalysts) before going on to consider firstly catalysis by the gold nanoparticle itself followed by catalysis by ligands attached to gold nanoparticles, all considered with a focus on biological molecules.
\end{abstract}

Keywords: gold-protein; gold-DNA; protein remodeling; artificial capsid

\section{Introduction}

Gold nanoparticles (GNPs) have a long history; Michael Faraday produced the first gold colloids in 1856 [1,2] and some of them survive to this day and have been displayed, flocculation-free at the Royal Institution [3]. Using gold as a catalyst, however, is a more recent breakthrough: It was long assumed that gold would not be a good catalyst because of its famously noble qualities. This changed with the discovery that GNPs could act as superior catalysts. Most notable was work by Haruta et al., showing that GNPs were able to catalyze aerobic oxidation of carbon monoxide [4]. This breakthrough 
was important not only for the gold catalysis field but was also a landmark in nanotechnology as it demonstrated how materials at the nanoscale may have remarkably different properties compared to the bulk: It was after all GNP clusters which demonstrated the interesting catalytic properties, not bulk gold.

While the development of GNPs as catalysts for non-biological reactions has developed apace, less work has been carried out on their ability to catalyze the reactions of/on biological molecules. It is not clear if this is simply because such effects have been less thoroughly investigated or is due to fundamental physical/chemical features of the GNPs which make them more difficult to utilize in such reactions. In this article we will briefly consider why GNPs are attractive for use in biology. Secondly, templating of GNPs by biological molecules (DNA and protein) that allows their precise arrangement is considered. Proteins and DNA can act as such scaffolds and recent advances in bionanotechnology allow them to be arranged in a programmable fashion in two and three dimensions. This provides arrangements where the GNP position can be precisely controlled, delivering a possible framework for production of novel catalytic structures

Finally, we turn our attention specifically to biological catalysis both by the GNP itself and by biological ligands coating its surface.

\section{Why Use GNPs in Biology?}

Although the catalytic properties of GNPs may be underused in biology, GNPs themselves enjoy wide application in the life sciences. This is for a number of reasons. Firstly, GNPs are relatively easy to synthesize, with a variety of well-established methods published that also allow control of particle size [5-8] and shape [9]. Gold's reputation for inertness means it is often presumed to be safe for in vivo use. We now know of course that GNPs can be highly reactive and therefore, potentially toxic. Tests on cells, for example have demonstrated size-dependence of toxicity, showing that $1.4 \mathrm{~nm}$ diameter GNPs are particularly toxic, causing cell death by necrosis in a matter of hours [10]. GNPs are synthesized with a variety of coatings which also seem to effect toxicity: Commonly employed triphenylyphosphine monosulfonate liganded $1.4 \mathrm{~nm}$ ( $\sim 55$ atom) particles appear to be considerably more toxic than similarly sized particles capped with glutathione [11]. The reason for the toxicity of GNPs is currently unclear, but it has been suggested that an increase in oxidative stress caused by the particles is likely [11]. These findings do not mean that, in a reversal of previous beliefs, GNPs are too toxic to be compatible with in vivo use, rather, toxicity appears to depend on size and surface ligand and as such it can potentially be controlled.

Another reason that GNPs may be valuable in biology relates to their plasmonic properties, something that makes them highly useful as sensors for detecting biological molecules [12]. For many years, thin layers of gold have been used in commercially available surface plasmon resonance detector [13] devices, which are able to sense binding events between biological molecules (such as antibody-antigen binding). The technology allows measurements to be made in solutions mimicking physiological conditions and in real time.

The plasmonic effects of GNPs have also allowed convenient colorimetric assays to be developed. These are typically based on the fact that (spherical) gold colloids with particle diameters in the range approximately five to a few tens of $\mathrm{nm}$ are red in color, becoming increasingly purple/blue at larger sizes $[14,15]$. When small GNPs aggregate the aggregates also appear blue [16]. Thus aggregation of 
small GNPs is observable as a color change from red to blue. This simple effect has proven very powerful due to the fact that GNPs can be easily modified to provide various chemistries for attachment of ligands/receptors of choice. These bound molecules have the ability to link GNPs together typically because they have two or more functional groups, each of which can bind to a GNP/GNP-surface-bound molecule possibly via a bridging molecule(s). In this way particles are linked together to form aggregates when the molecule of interest is present, accompanied by the associated color change. As a result, GNPs have been widely used in biological sensing [17,18]. Most famously this has resulted in pregnancy tests where gold particles are decorated with secondary antibodies to human gonadotropin hormone (hCG) and subsequently bind to primary antibodies to the same, arranged over a small surface area. This results in concentration of the gold particles in the small area and consequently a color due to plasmonic effects can be observed [19,20]. Other examples utilizing such plasmonic effects include the attachment of DNAzymes to GNP surfaces (discussed below).

The thermoablative properties of GNPs are an interesting area of medical application. This hyperthermic effect is typically achieved using either near infrared light (NIR) or radiofrequency (RF) radiation some of which is absorbed by the GNPs and converted to heat. However, producing gold nanoshells or lower symmetry GNPs such as gold nanorods [21,22] shifts the absorption peak from the visible region to the NIR $(800-1200 \mathrm{~nm})$. This is useful as NIR light is able to penetrate more deeply in living tissue [23,24]. The first report of the use of GNPs in this way was in 2003 [25], where gold-on-silica nanoshells were used. Gold's thermal properties have since been confirmed in numerous reports to have possible in vivo application [26]. If GNPs are localized to tumors, the thermoablative effect may be sufficient to kill tumor cells but not healthy tissue and this is recognized as a potentially useful therapy [27].

Finally, GNPs have a use in surface enhanced Raman spectroscopy in which the chemical nature of the molecules of interest, including biological molecules, can be probed using Raman scattering of laser light. The signal from molecules on GNPs is enhanced several orders of magnitude due to localized surface plasmon resonance effects on the nanoparticle surface [28].

In the rest of this article the following forms of interaction of GNPs with biological molecules will be considered:

- Templating: This refers to templating of GNPs by biological molecules. Here the ability of biological molecules to assemble into ordered arrays is used to provide a scaffold upon which GNPs can be assembled. This provides ordered, potentially programmable patterns of GNPs, which may be useful for biosensors and/or catalysis.

- Catalytic Effects: Here the catalytic effects of GNPs are considered. This is further subdivided into catalysis by the GNP itself, where the gold atoms on the GNP surface are the catalysts, and catalysis by the ligands, in which the molecules attached to the surface of the GNP are responsible for the catalytic effect and the GNP plays an important scaffolding role. In both cases catalysis relevant to biological molecules is considered particularly where the GNPs carry out catalytic function usually performed by a biological molecule and/or perform catalysis on a biological molecule. 


\section{Templating}

This section summarizes some of the work in the bionanoscience field involving templating of GNPs. Specifically it looks at examples of interactions of GNPs with DNA, and with protein. As extensive reviews are already available which include this topic [17,18], priority will be given to interactions which result in specific structures with potential catalytic usefulness i.e., where the biological molecules act as templates for production of novel gold nanostructures.

\subsection{Templating by DNA}

The discovery of the double helical structure of DNA and the nature of the base pairing which holds it together [29] has allowed researchers to utilize simple rules to design and control patterns of DNA assembly. At the same time, DNA synthesis technology has allowed the cheap and facile production of DNA strands of up to 100 bases in length. Numerous modifications to the DNA backbone and termini such as phosphorothioates, amines, thio groups, and biotin can also be included to provide moieties for specific binding of other molecules of interest. All of these breakthroughs have allowed the design of new DNA structures, different from those found in nature, and their decoration with particles, including GNPs, that can be positioned with sub-nanometer accuracy [30-33]. There are a number of ways to attach GNPs to double stranded (ds) DNA templates. Phosphorothioate modified DNA for example has been used to bind GNPs to specific points on a dsDNA backbone via a bifunctional "molecular fastener" molecule [34], derived from $N, N^{\prime}$-bis( $\alpha$-iodoacetyl)-2-2'-dithiobis(ethylamine) (BIDBE) [34,35] (Figure 1).

Perhaps the simplest template that (ds)DNA can offer takes advantage of its high aspect ratio to provide a scaffold for the production of metallic rods and nanowires which may have use in electronics and photonics [36], sensing devices [37], or as catalysts [38]. Indeed, while canonical GNPs are typically roughly spherical in shape, the catalytic potential of gold nanorods is already appreciated [39] and a number of reports have demonstrated production of DNA-templated gold nanowires [40-45].

GNPs arranged with high regularity and density over large surface areas may also prove to have useful catalytic roles as has been shown by similar arrays manufactured by methods that do not utilize biological templates [46]. DNA can provide such a template due to the fact that it can be designed to form self-assembling "tiles" which can pattern a large surface area with high regularity. Early examples of the production of designed DNA nanostructures include regular tiling by DNA double crossover (DX) motifs [47] (Figure 2). DX motifs consist of two double strands of DNA linked together by the crossing over of single strands from one ds into the neighboring ds. Using DX DNA gives DNA tiles the necessary rigidity required if they are to regularly tile a large surface area with reduced deformation. In the example shown in Figure 3, DX DNA is designed to provide a small, rigid, triangular structure with "sticky ends" which could regularly tile large 2D surfaces [48]. The addition of thiol groups at free 5' ends of one of the DNA strands in each triangle provides a site for attachment of 5 and $10 \mathrm{~nm}$ gold nanoparticles resulting in a patterned array of GNPs [32]. Similarly modified DNA strands have been used to form lines of GNP "wires" on 2D DNA arrays [49]. 
Figure 1. BIDBE binds to Phosphorothioate DNA (PS-DNA) to form BIDBE-PS-DNA, which can then be reduced to form bifunctional linker (BF) attached to PS-DNA. BF provides a sulfhydryl group for attachment to GNPs. Reprinted (adapted) from Ref. [34], with permission from Wiley. Copyright 2007 WILEY-VCH Verlag GmbH \& Co. KGaA, Weinheim.
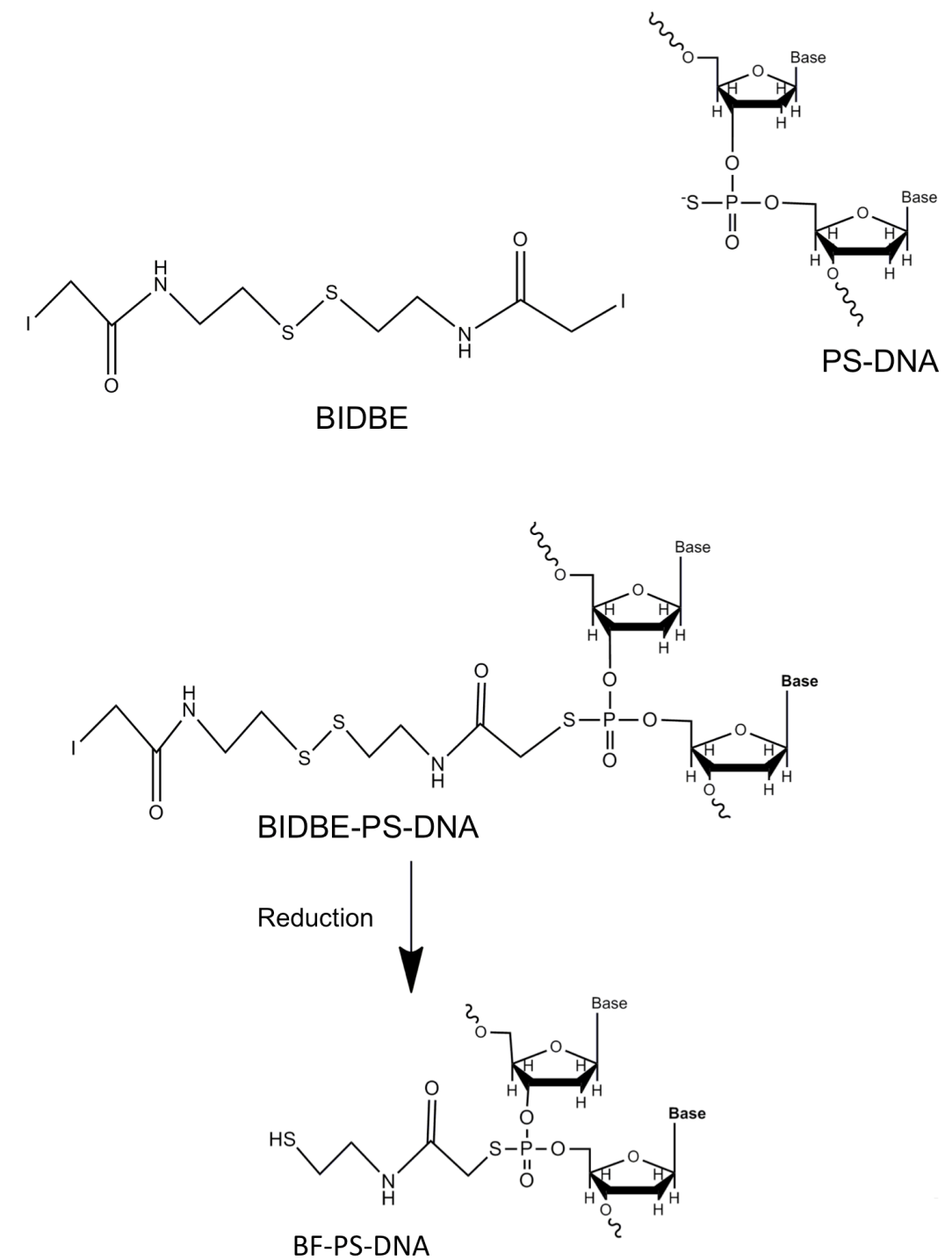

Figure 2. A schematic of DX DNA. Each single strand of DNA is shown in a different color. Small circles represent the position of each phosphate and vertical grey lines represent the base pairs. Note that the red, green, and pink strands cross over between both double helices. Reprinted with permission from Ref. [48] Copyright 2004 American Chemical Society.

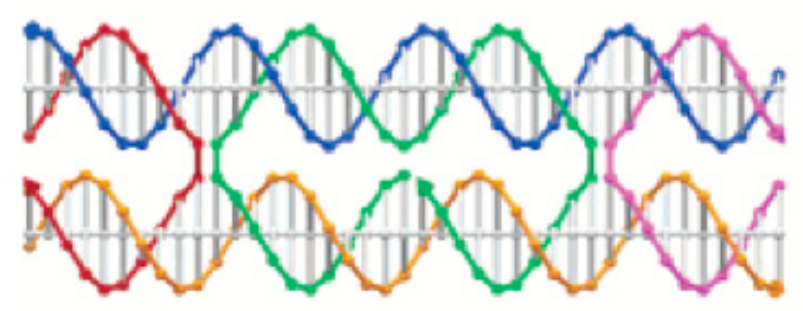


Figure 3. (a) DX DNA triangles can be made with sticky ends so that the triangles will tile together; (b) Not all the DNA ends are required for tiling and free ends can be attached to GNPs of 5 or $10 \mathrm{~nm}$ diameter (yellow); (c) AFM imaging of the DX array without addition of gold shows its regular structure; (d) When gold is attached, a regular array of GNPs can be formed on the DX DNA template, as shown by the TEM micrograph of a DX DNA array with alternating $5 \mathrm{~nm}$ and $10 \mathrm{~nm}$ GNPs attached. Only GNPs are visible in this image. (a)-(d) reprinted (adapted) with permission from Ref. [32]. Copyright 2006 American Chemical Society.

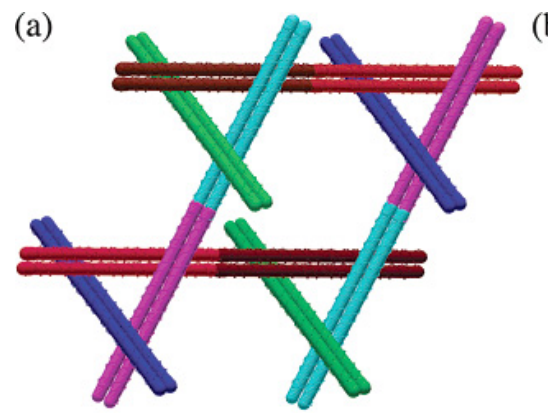

(b)

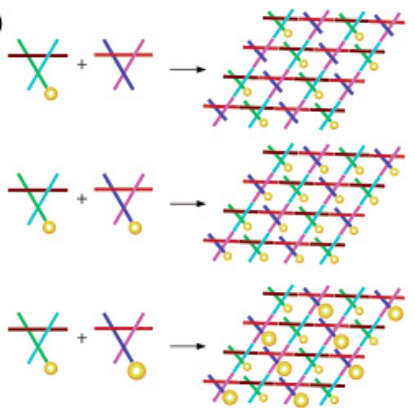

(d)

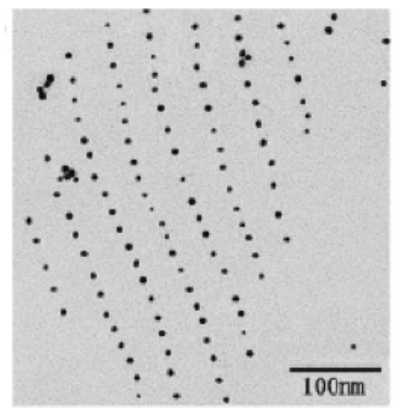

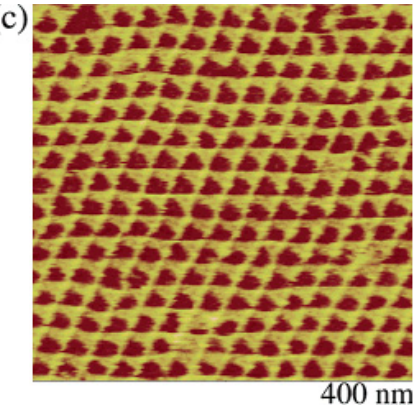

Figure 4. A DNA pyramid can be constructed using four DNA strands [50]. (a) Free DNA ends at each vertex can be modified with a linker sequence to attach GNPs; (b) Transmission electron micrograph of a single DNA pyramid-GNP complex with the four GNPs visible as black circles. Reprinted with permission from Ref [50]. Copyright 2009 American Chemical Society.

(a)

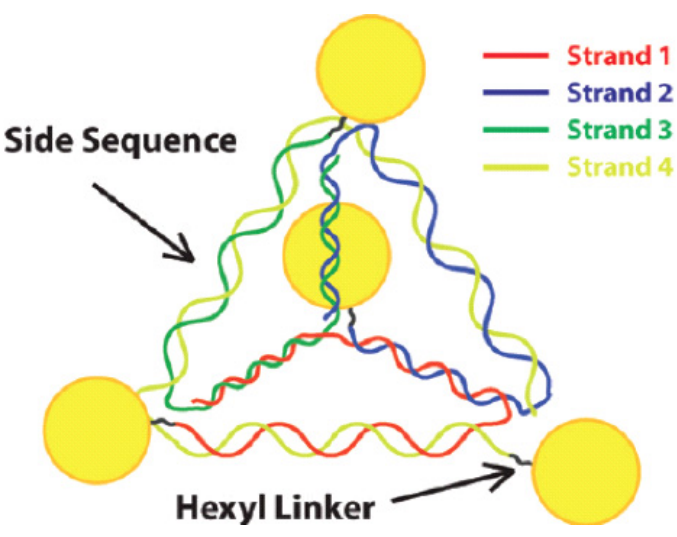

(b)

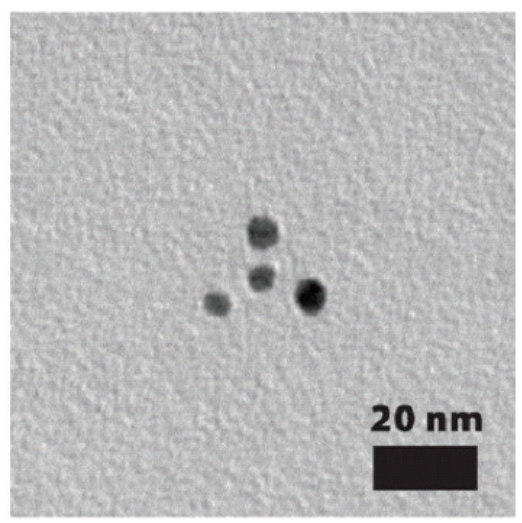


Sophisticated catalysis, equivalent to enzyme-catalyzed reactions, may require the control of participating atoms and molecules precisely in three dimensions. DNA nanotechnology can also address this: Small, three-dimensional structures made from several strands of DNA have been produced including cubes [51], a bipyramid [52], and octahedra [53]. GNPs of $5 \mathrm{~nm}$ diameters have been attached to the vertices of pyramidal DNA nanostructures [50] (Figure 4). The invention of DNA origami [54] has further advanced the field allowing the relatively facile construction of bespoke $2 \mathrm{D}[54]$ and $3 \mathrm{D}$ structures such as boxes [55,56].

One of the most intriguing results illustrating the power of DNA to arrange GNPs into structures with particular physical/chemical properties is shown by synthesis of a DNA origami rod with thiol groups at particular points on the surface such that GNPs attach at points tracing the backbone of a helix on the rod's surface. These shapes were shown to be chiral plasmonic structures [57] (Figure 5).

Figure 5. (a) A DNA origami rod (grey) can be synthesized with outward facing staple strands which contain a thiol group. Versions can be made where thiols can trace either a left-handed or right-handed helical path over the surface of the rod; (b) GNPs can be attached to the thiols and the resulting helical arrangement visualized via TEM. Reprinted by permission from Macmillan Publishers Ltd from ref. [57] copyright 2012.
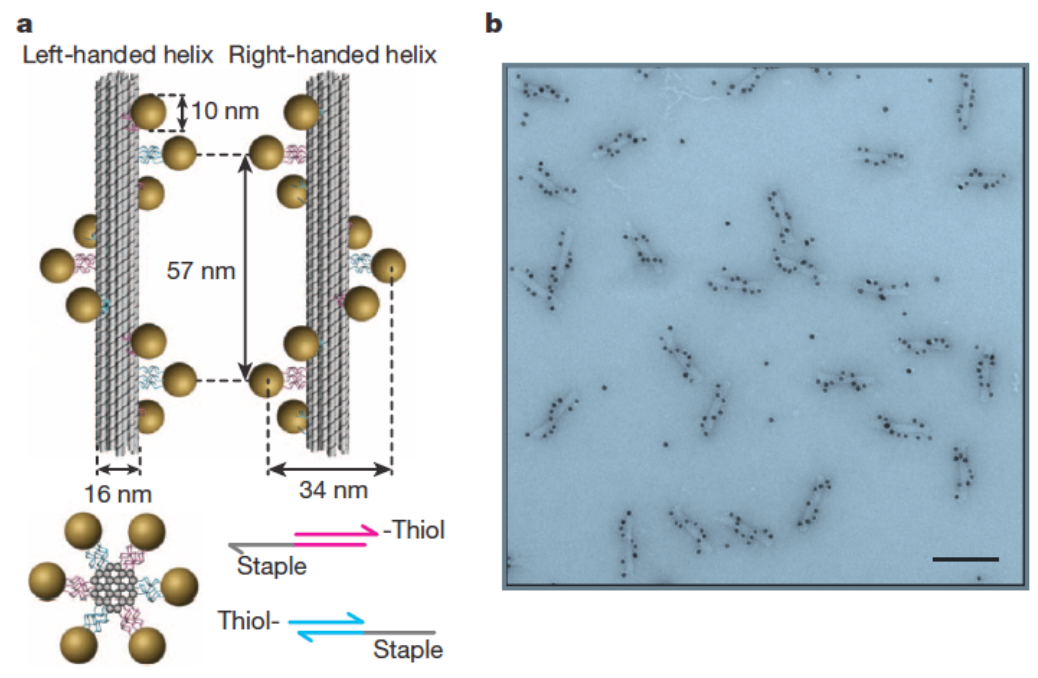

\subsection{Templating by Protein}

Proteins are the workhorses of life and offer arguably the most structurally and mechanistically sophisticated scaffolds for nanoparticle assembly. GNPs have been incorporated into proteins and examples include prion proteins, virus capsids, and chaperonins. Catalysis by metals other than gold deposited on viral templates has been demonstrated e.g., palladium [58] and iridium [59] for catalysis of dichromate reduction and oxidation of water respectively.

In the case of prions, the $N$-terminal middle (NM) region of Saccharomyces cerevisiae Sup35p protein was used [60]. This protein forms self-assembled amyloid fibers of approximately $10 \mathrm{~nm}$ in diameter [61]. The length of the fibers can be crudely controlled by manipulation of the assembly conditions. When amino acid 184 of NM is mutated to cysteine the resulting protein fiber can be used as a template for gold nanowire formation via a thioaurate bond formed between $1.4 \mathrm{~nm}$ diameter 
GNPs and the sulfur of the cysteine side chain. Subsequent "enhancement" of the deposited GNPs resulted in the templated formation of a solid gold nanowire [60].

The second protein template is the virus capsid. Capsids can provide useful hollow nanoshells that have a wide variety of applications [62]. One such example is cowpea mosaic virus (CPMV), an icosahedral virus constructed from 60 identical protein subunits [63]. CPMV has been shown to be a potentially useful scaffold for catalyst production: It has been decorated with redox active methyl(aminopropyl)viologen [64] or ferrocene [65] moieties via attachment to surface carboxylate or amine groups respectively. The resulting particles show promise for use in electrocatalytic processes [62].

Figure 6. Cowpea Mosaic Virus (CPMV) can be modified to bind GNPs. (a), (c), and (e) show unstained TEM images of GNPs bound to different cysteine mutants of CPMV with GNPs visible as black circles. Scale bars are $5 \mathrm{~nm}$; (b), (d), and (f) show models of CPMV with GNPs bound to modified sites. Reprinted with permission from Ref. [66]. Copyright 2004 American Chemical Society.

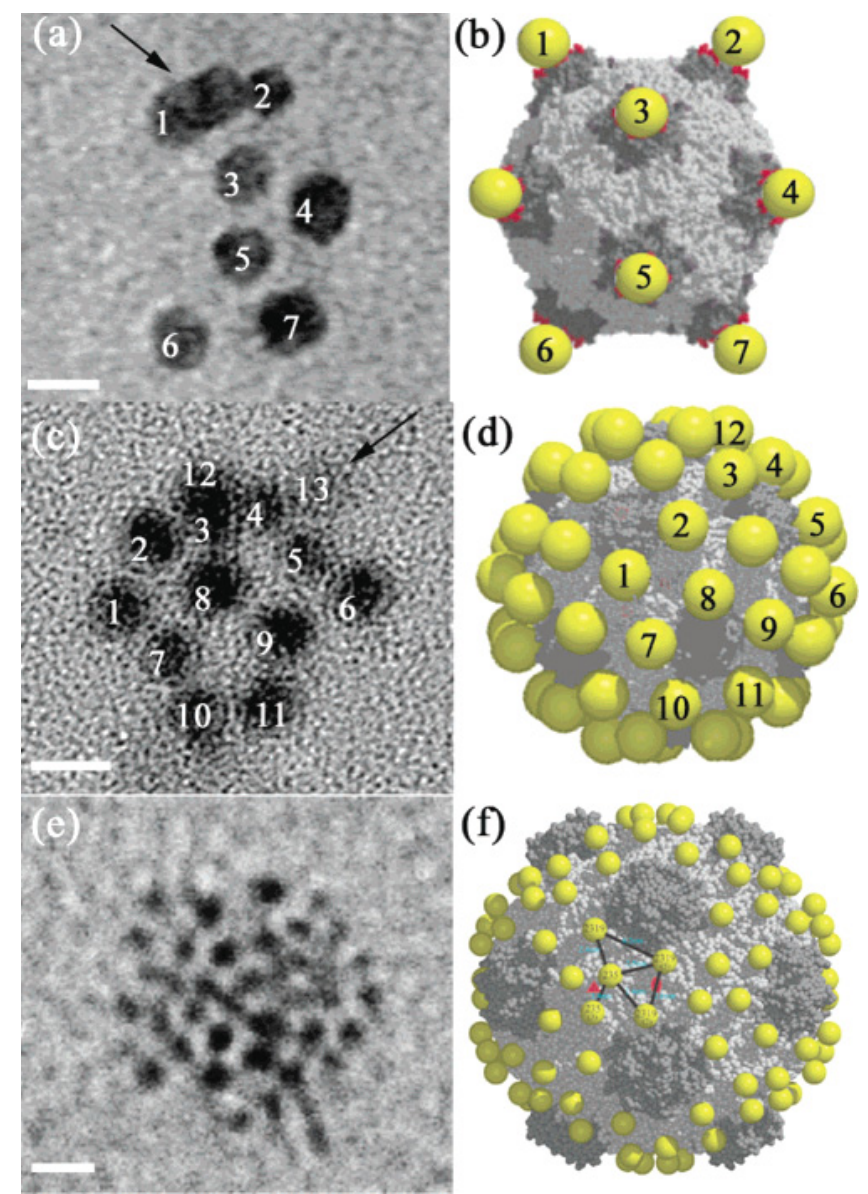

A report by Blum and colleagues demonstrated the attachment of GNPs to the exterior of the CPMV capsid [66]. Cysteine residues can be introduced on the external surface (the virus has no naturally occurring surface cysteines) and, as the structure of the protein is known, cysteines can be placed where required and will be repeated at all 60 symmetry-equivalent positions. Three different positions for cysteines were chosen in order to give a different number of particles and variable interparticle distances between attached GNPs and 5 or $10 \mathrm{~nm}$ diameter GNPs were attached at the 
designated positions (Figure 6). According to the authors, virus capsids decorated in this way have many potential uses including as catalysts [66]. CPMV would tolerate further surface modification which could allow attachment of nanoparticles of different metals in addition to GNPs which could allow the production of finely controlled bimetallic or multicomponent catalysts which are highly valuable [67].

Tobacco mosaic virus (TMV) is widely used as a tool in bionanoscience [68] and it has been decorated or coated with a number of metals including iron oxide, $\mathrm{CdS}, \mathrm{PbS}$ and $\mathrm{SiO}_{2}$ [69], and $\mathrm{TiO}_{2}$ [70]. Ag, Pd, and Pt nanoparticles have also been deposited [68,71], as has gold, using genetically modified virus [71-73]. Attachment of a high density of $6 \mathrm{~nm}$ diameter GNPs to unmodified TMV in simple aqueous solution was recently reported [74]. The use of nanoparticle-decorated TMV as a catalyst has been demonstrated by the formation of palladium nanoparticles on the surface of TMV, which were shown to catalyze dichromate reduction [58]. To date catalysis via gold-coated virus particles has lagged behind these other materials.

Protein crystals have been used to template GNPs, including cross-linked [75] and non-cross-linked lysozyme [76]. In the latter case, crystals of lysozyme, when grown in the presence of $\mathrm{ClAuS}\left(\mathrm{CH}_{2} \mathrm{CH}_{2} \mathrm{OH}\right)_{2}$, resulted in in situ formation of GNPs within the protein crystal through a disproportionation process [76]. This growth was much slower than GNP formation in the absence of protein, allowing fine control of GNP size up to $20 \mathrm{~nm}$ in diameter. The GNP-containing lysozyme crystals were subsequently shown to be able to catalyze the reduction of $p$-nitrophenol to p-aminophenol [77].

Figure 7. (a) Negatively stained TEM image of beta chaperonin which forms a 2D crystal; (b) Negatively stained TEM image of beta chaperonin mutant with increased pore size; (c) Schematic of (a) showing $5 \mathrm{~nm}$ GNPs (yellow) binding in the $3 \mathrm{~nm}$ pores; (d) Schematic of (b) showing $10 \mathrm{~nm}$ GNPs binding in the $9 \mathrm{~nm}$ pores. Reprinted by permission from Macmillan Publishers Ltd from ref. [78] copyright 2002.

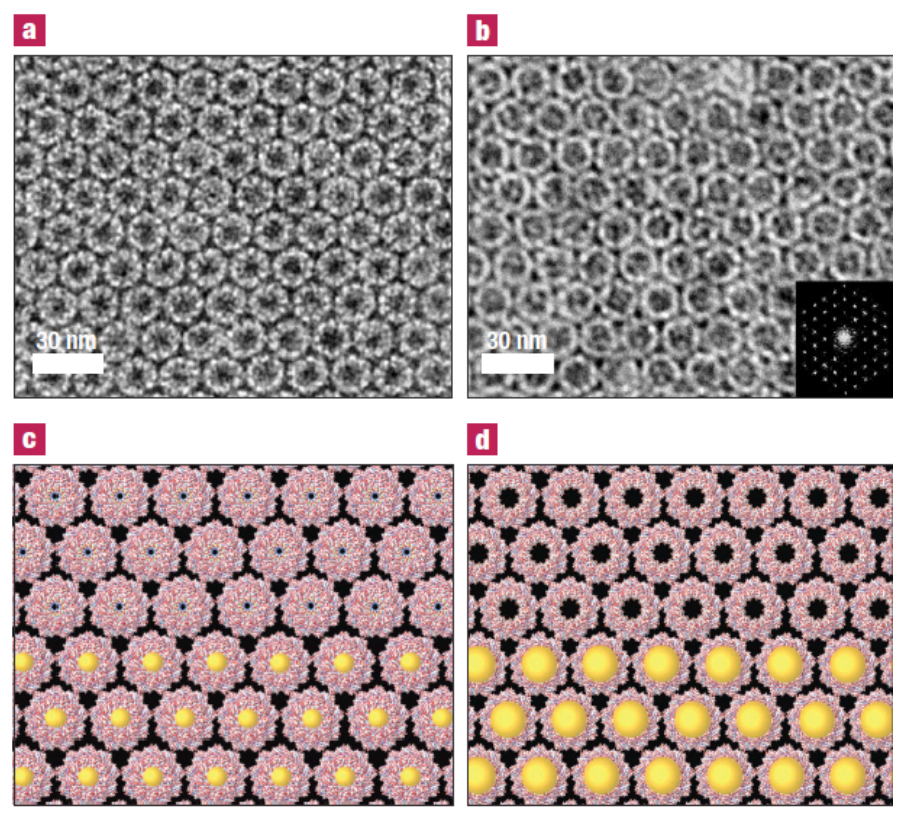


A final example of protein scaffolds involved the use of chaperonin protein HSP60 as a template for the regular arraying of GNPs as reported by McMillan et al. [78]. In this report, the $60 \mathrm{kDa}$ beta subunits from Sulfolobus shibatae were used. These proteins form a double ring structure containing a total of 18 protein subunits, which is known to be able to form $2 \mathrm{D}$ crystals $[79,80]$. The single native cysteine present in the proteins was removed and structural information was used to place cysteines at positions around the opening to the central cavity of the protein. Cysteines were added to line the opening to the hole at a diameter of $3 \mathrm{~nm}$ or $9 \mathrm{~nm}$ (in the latter case residues were removed to make the opening larger). 2D crystalline arrays of the GNPs were achieved either by first forming the 2D protein arrays and then adding the GNPs in solution or by first binding the GNPs to the proteins followed by deposition on a surface (Figure 7).

\section{Catalytic Effects of GNPs on Biological Molecules}

The use of GNPs as catalysts in a wide variety of reactions is a growing. Perhaps less well known is the use of GNPs to catalyze reactions on or of biological molecules. This is a nascent area but one which could have interesting potential. In this section, two categories will be considered: Firstly, catalysis by the GNP itself. Secondly, catalysis by ligands on the GNP surface.

\subsection{Catalysis by GNP Itself}

In this section we will firstly consider features of the "standard" GNP-catalyzed reactions, which are carried out by GNPs themselves, often deposited on an oxide surface. Subsequently, two rare examples where the GNP itself appears to directly catalyze reactions of biological molecules will be considered.

The catalytic abilities of GNPs were first brought forward by Haruta [4] in a reaction where GNP was shown to catalyze the oxidation of carbon monoxide. Since that time, GNP-based catalysis of numerous non-biological reactions have been discovered and characterized (see, for example, Bond et al. [81], Hashmi et al. [82], and Pina et al. [83] for comprehensive reviews).

A number of important features required for catalysis by the GNP are proposed or recognized including: (1) Low coordination: Mills et al. [84] showed via theoretical modeling that small gold clusters or rough gold surfaces were catalytically active because they contained isolated gold atoms with low coordination such that they have HOMOs which protrude into space rather than being delocalized. It was proposed that this should allow transfer of charge into the $\pi^{*}$ orbital of $\mathrm{O}_{2}$ to easily occur. (2) Size: Size plays an important role with a general trend towards increased catalytic rate with smaller gold particles [85] this trend is not surprising given that only the surface atoms are involved in catalysis. In the light of point 1 above, smaller clusters are more likely to have a higher proportion of atoms of low coordination through edges and imperfections. In addition, certain geometries and sized of clusters seem to have special properties. So-called "magic-number" [86] particles such as $\mathrm{Au}_{55}$ appear to be closed-shell clusters and have been shown to be in fact highly resistant to oxidation and for this reason may be particularly good oxidation catalysts [87]. (3) Interface with scaffold: GNPs are typically on an oxide support and the nature and relevance of the interface between the two has been investigated: The point at which the GNP meets the support has been proposed to be the center of oxidation [88]. Smaller GNPs are thought to be more active because they have a larger proportion of 
their structure in contact with the support. In the case of $\mathrm{CO}$ oxidation, the gold in contact with the support is proposed to be $\mathrm{Au}^{3+}$ and it is this cationic gold that is suggested by some to be the active sites for dioxygen activation [88]. In the cases discussed above, where the scaffold is a biological molecule such as DNA or a virus capsid, the effects on the catalytic activity of gold are less well characterized. However, enzyme catalysts show us that precise arrangement of atoms and residues are required to constitute an effective active site [89] and it is reasonable to imagine that controlled, accurate placing of GNPs into three-dimensional assemblies may be of use in future catalysis design. In addition the arrangement of numerous GNPs at high density on a capsid could conceivably lead to cooperative catalytic effects. Biological molecules of course, typically exist in aqueous solution and GNPs too can carry out catalysis free in solution rather than on a support [90]. These reactions are less well-studied but are perhaps more relevant with regards to biocompatibility. 4. Adsorption mode: According to theoretical work [91] $\mathrm{O}_{2}$ activation by adsorption onto the GNP surface can occur by one of three modes: end-on, top-bridge-top and bridge-bridge the most easily activatable $\mathrm{O}_{2}$ corresponds to most easily dissociated from the GNP surface which is bridge-bridge mode (see also Della Pina et al. for a brief review [83]).

In terms of biological effects, there are a number of examples where inorganic nanoparticles have been shown to mimic the action of proteins [92]. This also includes mimicking of enzyme catalysis. GNPs have been found to mimic the action of glucose oxidase (GOx). GOx is the enzyme which catalyzes the oxidation of glucose to glucolactone, simultaneously producing hydrogen peroxide (Figure 8A) [93]. This reaction provides the basis for many blood glucose meters used by people with diabetes. Diabetes is a serious and growing problem; the worldwide incidence of the disease was estimated to be $2.8 \%$ in 2000 projected to grow to $4.4 \%$ by 2030 [94], equal to 171 million and 366 million people respectively [94]. The disease is characterized by high blood sugar, which occurs either due to insufficient production of insulin (Type 1) or an inability to utilize insulin correctly (Type 2). Numerous acute and long-term complications result from the disease.

Figure 8. (A) Glucose oxidation to gluconolactone catalyzed by glucose oxidase (GOx). (B) Utilization of the GOx-like catalytic activity of Gold NPs to produce a sensor for detection of DNA hybridization. In this scheme, GNPs (red) are able to catalyze oxidation of glucose, producing peroxide. This can be utilized by horseradish peroxidase (HRP) to oxidize ABTS resulting in a color change (path a). Production of peroxide also catalyzes reduction of $\mathrm{AuCl}_{4}$ to $\mathrm{Au}^{0}$ leading to increase in GNP size (path b). (A) Reproduced (adapted) with permission from Ref [93] copyright The Biochemical Society.; (B) reproduced from Ref. [95] with permission from Wiley. Copyright 2011 WILEY-VCH Verlag GmbH \& Co. KGaA, Weinheim.
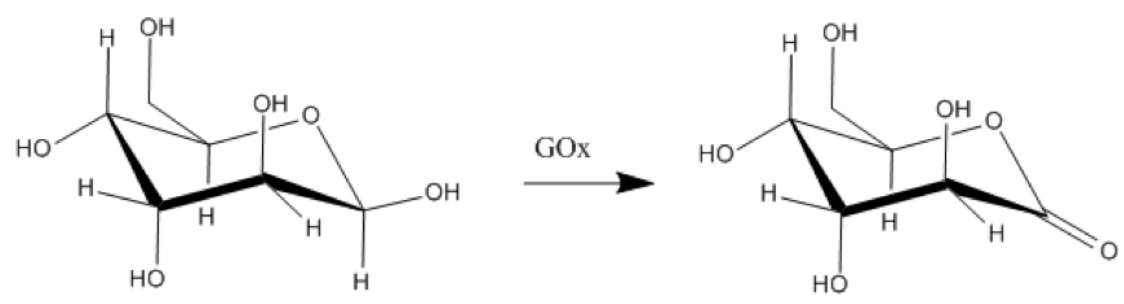
Figure 8. Cont.

B

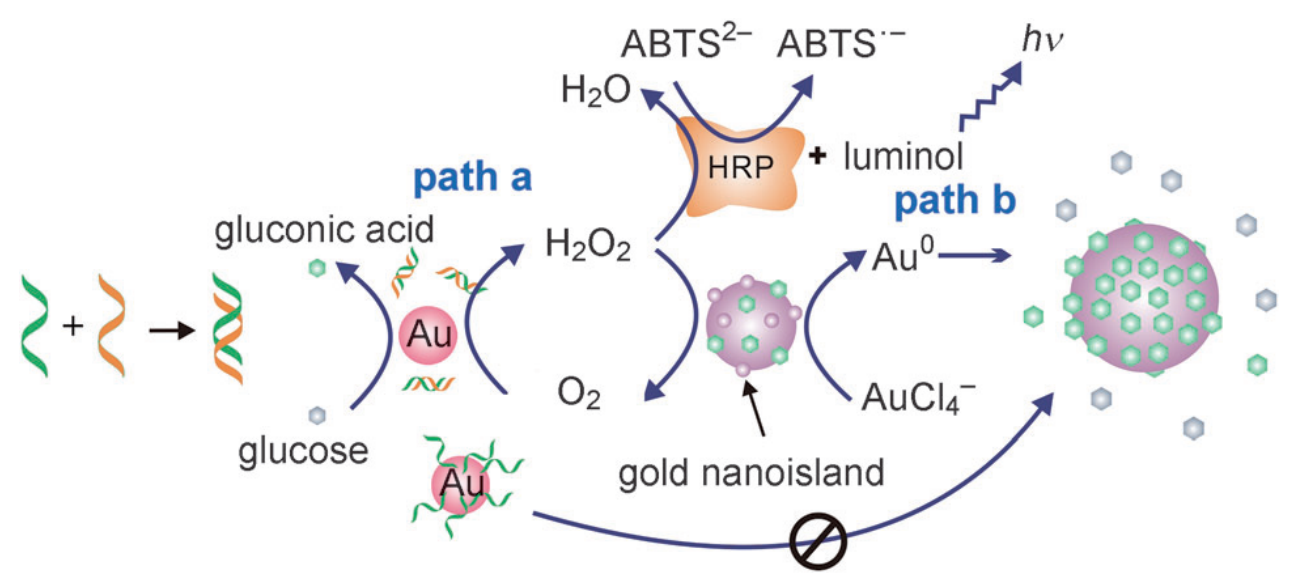

Insulin is an effective treatment for diabetes, particularly Type 1 and its best use requires the ability to accurately monitor levels of blood glucose. A typical monitoring device takes a small volume of blood and uses GOx to oxidize it. The enzyme is regenerated via oxidation with a mediator, which in turn transfers the electrons to an electrode in the device, generating a current. The size of current generated is proportional to the amount of glucose in the sample. Sensors based on this technology have been hugely successful [96]. It has been shown that GNPs are able to catalyze the same oxidation reaction of glucose, producing gluconic acid and hydrogen peroxide (1) [90,97]:

$$
\text { Glucose }+\mathrm{O}_{2} \rightarrow \text { gluconic acid }+\mathrm{H}_{2} \mathrm{O}_{2}
$$

GNPs have been found to be effective catalysts of the oxidation of glucose both in solution [90] and on a solid support [98]. In solution the GNP was found to show increasing catalytic rate of the conversion of glucose to gluconate as the diameter of the particle was decreased, up to the lowest diameter tested $(3.6 \mathrm{~nm})$ for which $21 \%$ of the glucose was converted in the first $200 \mathrm{~s}$ of the reaction. Although the catalytic activity was still an order of magnitude lower than a commercial enzyme system [98] it can be expected that the rate would improve if smaller particles were employed. Luo et al. [99] investigated this catalysis further and showed that passivation of the GNP surface inhibited the catalysis, implicating a role for surface $\mathrm{Au}$ atoms. Furthermore, the catalysis showed Michaelis-Menten behavior with a $K_{\mathrm{m}}$ of $6.97 \mathrm{mM}$ (compared to $4.87 \mathrm{mM}$ for GOx) while the $K_{\text {cat }}$ of the GNPs was two-fold higher. Testing of other metal nanoparticles showed no effect on glucose oxidation. Interestingly, the authors showed that the GNP catalysis was size dependent and was also active over broader ranges of $\mathrm{pH}$ and temperature than GOx giving it obvious potential as a robust component in glucose monitoring devices.

The ability of GNPs to catalyze oxidation of glucose has been utilized for detection of DNA hybridization [95] (Figure 8B). In this work the peroxide produced by the catalytic effect of the GNP is coupled to horseradish peroxidase (HRP) oxidation of ABTS $^{2-}$ (2,2'-azino-bis(3-ethylbenzothiazoline6-sulfonic acid) which results in a blue color [95]. dsDNA does not strongly bind to the GNPs and so does not have a significant effect on the reaction. Single stranded (ss)DNA, however, shows significant binding [100,101], resulting in passivation of the surface. Thus the system can be used to probe for complimentary strands of DNA or RNA (e.g., disease-associated miRNAs) using colorimetric assays or direct observation of GNP size and/or plasmonic effects (which arise due to the 
fact that the peroxide produced can be used to reduce $\mathrm{AuCl}_{4}$ to $\mathrm{Au}^{0}$ which is deposited on the GNP causing an increase in particle size, a process inhibited by attached ssDNA).

The final example is an apparent GNP catalysis of structural changes of a biological molecule: In this case GNPs appear to catalyze protein remodeling. It is well known that GNPs may interact with proteins and may cause structural changes. However, such changes are usually a loss of structure or function due to denaturation of the protein or formation of an aggregated protein "corona" around the GNP [102-104]. The GNP-induced formation of higher order structures is unheard of. In our work reviewed here the protein TRAP (trp-RNA binding attenuation protein) was used. TRAP is a toroidal protein found in species of Bacillus. In vivo TRAP is involved in the feedback control of tryptophan synthesis [105]. The crystal structures of the TRAP from both B. stearothermophilus [106] and $B$. subtilis [107] are known and show that TRAP is approximately $8 \mathrm{~nm}$ in diameter and consists of 11 identical monomers, each of around $8.4 \mathrm{kDa}$. As well as an interesting and well-defined shape, the protein has other properties useful to bionanoscience, these include high thermostability [108] and ability to tolerate many surface mutations without a change in overall structure. To date, TRAP has been used to produce symmetry altered structures [109], as a component of a floating nanodot gate transistor [110], and to construct a self-assembled protein nanotube [111].

The interaction of TRAP with GNPs is brought about by the mutation of lysines at position 35 (position 37 in B. stearothermophilus TRAP) to cysteine (Figure 9). Cysteines contain a sulfhydryl group and therefore have the potential to bind strongly to gold. However, there are no cysteines present in the wild type protein. Residue lysine 35 of TRAP is surface-accessible and lies exposed around the outer rim of the ring, and when it is mutated to a cysteine and then mixed with $1.4 \mathrm{~nm}$ GNPs, an interesting conformational transition is observed.

Figure 9. (a) Crystal structure of TRAP (pdb 1qaw) [106] Shown in two mutually orthogonal views. The protein is shown in cartoon format with residues at position 35 highlighted in yellow space-filling representation; (b) TEM image of purified wild type TRAP; (c) TEM image of purified cysteine mutant TRAP; (d) TEM image of wild type TRAP in the presence of GNPs; (e) TEM image of cysteine mutant TRAP in the presence of GNPs. Note the appearance of large structures. Scale bars $=40 \mathrm{~nm}$. (b-e) Reprinted with permission from Ref. [112]. Copyright 2012 American Chemical Society.

a
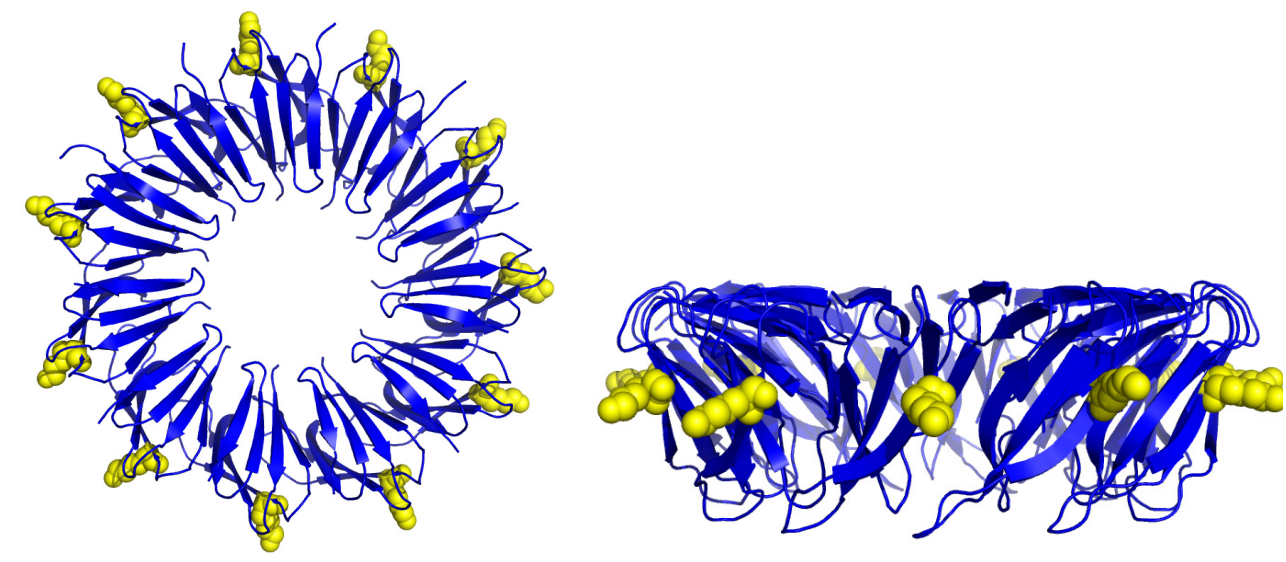
Figure 9. Cont.
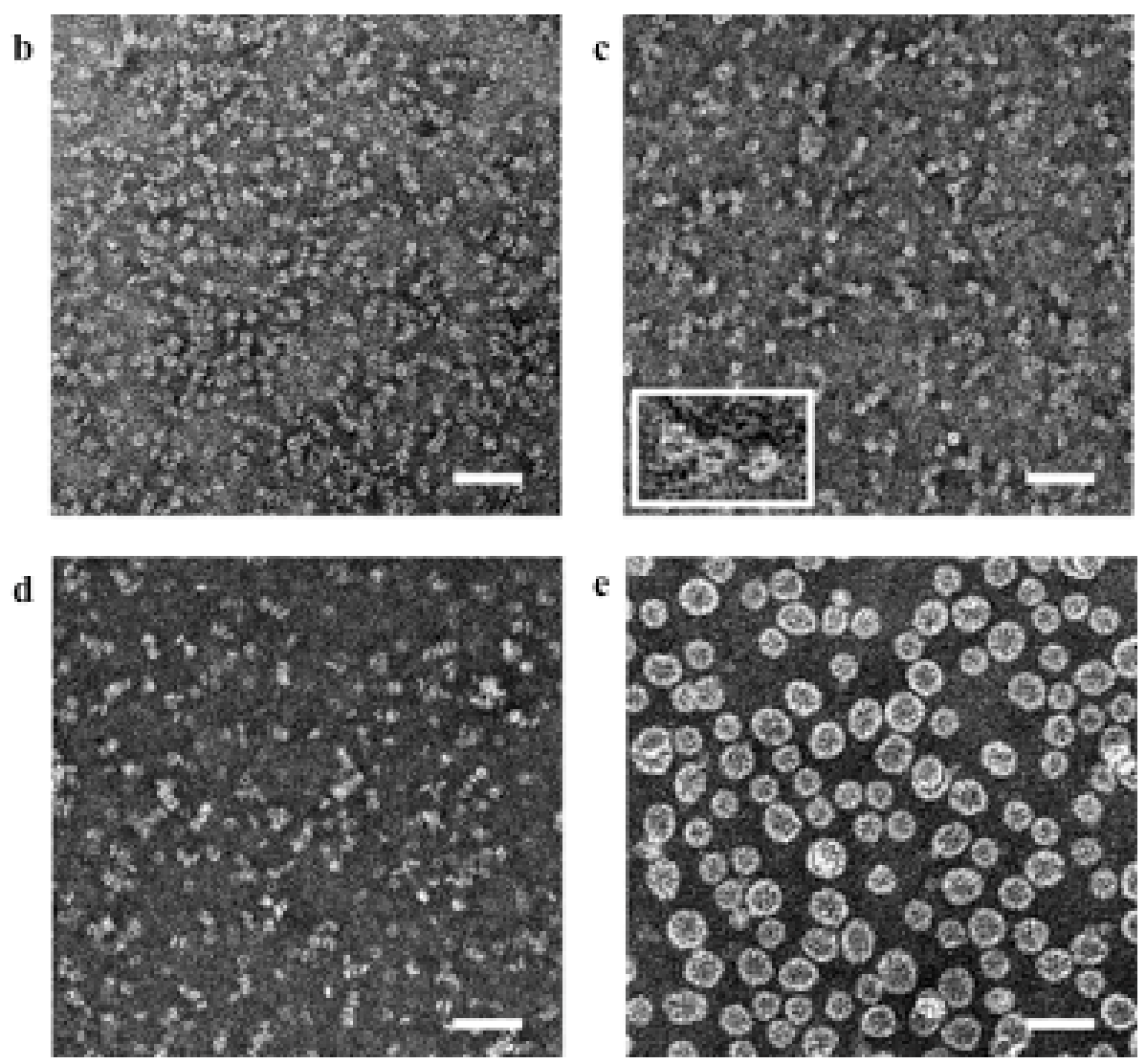

In the absence of gold particles the TRAP protein, as observed by transmission electron microscopy (TEM) appeared to be identical to the unmodified protein, i.e. it appeared as a small donut shaped ring approximately $8 \mathrm{~nm}$ in diameter (Figure 9). Addition of $1.4 \mathrm{~nm}$ GNPs to the wild type protein had no significant effect. However, addition of the same GNPs to the mutant protein caused a dramatic change. After several hours of incubation at $4{ }^{\circ} \mathrm{C}$, the mutant protein sample showed no evidence of the original ring-shaped protein, instead large, circular proteins, approximately $20 \mathrm{~nm}$ in diameter were observed. Analysis of these particles by cryo-electron tomography showed that the structures produced were in fact hollow protein spheres. The spheres appeared to exist as two discrete sizes (approximately $17 \mathrm{~nm}$ in diameter and approximately $21 \mathrm{~nm}$ in diameter) with the proportion of each depending on the relative concentration of gold (with the larger protein species predominating at low GNP concentrations). The resemblance of the produced hollow particles to virus capsids led to them being called "Capsid-like spheres" (CLS) [112]. Furthermore, the results suggest that while a small cluster of one or more gold particles were sometimes present at a single position within the protein shells, in other cases no gold particles could be observed associated with the shells (although it must be noted that $1.4 \mathrm{~nm}$ diameter gold particles are difficult to observe under TEM). This immediately suggested the possibility that gold was acting catalytically. Indeed given the mismatch between the size of the GNP and the size of the resulting protein shell, it is difficult to see how the gold could be acting via a simple templating or scaffolding effect. The catalysis hypothesis is supported somewhat by the fact that even low concentrations of GNPs are able to promote the same protein remodeling effect. 
While the catalysis hypothesis in this case is an attractive one it is currently unproven: the small size of the GNPs makes it difficult for their presence in the produced CLSs to be completely ruled out. Furthermore, while large numbers of GNPs appear to be absent from the CLSs, the presence of gold atoms has not been definitively ruled out.

Time course experiments [112] have offered some intriguing hints as to the possible course of the reaction: when the reaction is stopped and viewed under TEM one minute after the addition of GNPs, many of the stable TRAP rings have already disappeared but few CLS are yet formed, instead a large number of thread-like structures are visible which appear to be unfolded protein or disassembled ring. This suggests that apart of the GNP mechanism may involve breaking apart of the stable TRAP ring and (partial) unfolding of the monomer proteins before refolding/reassembly into the capsid form. The mechanism whereby this may occur is still currently unknown.

The precise role of the gold particles in inducing formation of the CLS remains to be explained, the fact that the reaction occurs only in the cysteine mutant of TRAP strongly suggests that interaction with the gold surface is important. It is not clear if this would be direct or via an oxygen intermediated as has been reported in other oxidative catalytic reactions of GNPs [113]. Gold adatoms on the surface of the GNPs may be the site of gold-sulfur bond formation [114]. The nature of the thiol-gold bond has recently been reviewed [114] and surprisingly it is only recently that the nature of gold-thiol interactions has become clearer with much still remaining to be understood [114].

The GNP-induced remodeling of TRAP into CLS is significant because to date the interaction of proteins with GNPs has generally been non-catalytic and non-specific, i.e. the usual effect is that protein denaturation occurs [115-117] or a "corona" forms around the GNP [118]. While this effect can be useful in some cases, the ability to remodel proteins is intriguing although it must be acknowledged that much work remains to confirm if the observed effect is truly catalytic and if so the details of the mechanism. If such a protein remodeling effect was found to be widely applicable then this form of GNP reaction could become a useful tool in bionanotechnology.

\subsection{Biological Catalysis by the Ligand}

In these reactions the active groups responsible for catalysis are the ligands attached to the GNP surface. Here the advantage of using gold is its ease of handling and simply the efficiency gains that may result from having a monolayer of catalytic ligand at high-density on a particle. The role of the ligand monolayer on GNPs has been extensively reviewed [119]. Biological reactions of course take place in aqueous solution and so GNP interaction with them might best be carried out using unsupported gold colloids in solution. Luckily, such GNPs do show catalytic activity in a range of reactions [120]

In one example, the reaction catalyzed was the cleavage of the phosphodiester phosphate bond [121]. A reaction which in vivo can be carried out by enzymes such as restriction enzymes [122] and topoisomerases [123]. GNPs of approximately $2.5 \mathrm{~nm}$ in diameter were produced and coated with an azacrown functionalized thiol. This contained triazacyclononanes which are able to bind transition metals including $\mathrm{Zn}^{\mathrm{II}}$ [121]. Initially, 2-hydroxypropyl $p$-nitrophenyl phosphate (HPNP) was used in place of RNA and the hydrolysis reaction was observed. The second-order rate constant for HPNP cleavage was found to be over 600-times higher than in the absence of the GNP, this was in part 
attributed to a local concentration effect and to transition state stabilization [121]. The produced supramolecule was also found to be able to catalyze the same cleavage of actual RNA dinucleotides. A more in-depth analysis [124] using triazacyclononane $\mathrm{Zn}$ (II) as the catalytic unit along with unreactive ligands, found maximum $\mathrm{k}_{\mathrm{cat}}$ and $K_{\mathrm{M}}$ values of $6.7 \times 10^{-3} \mathrm{~s}^{-1}$ and $3.1 \times 10^{-4} \mathrm{M}$ respectively. The maximum $k_{\text {cat }}$ value was reached when the mole fraction of the catalytic unit was 0.4 of the total ligands. Theoretical calculations showed this to be the point at which lone catalytic units no longer existed and all catalytic units worked in tandem.

In another example, decorated GNPs with esterase activity were produced [125]. Here, the GNP scaffold allows attachment of dipeptide functionality. Specifically, numerous copies of a histidine, and phenylalanine containing dipeptide moiety (HS- $(\mathrm{CH} 2) 11 \mathrm{CO}-\mathrm{HIsPhe}-\mathrm{OH})$ was attached to the surface of a GNP to simulate the active site of an esterase, which is known to contain these two amino acids, providing the imidazole and carboxylate groups to act as general base and general acid in the reaction [126]. The modified particles were tested against the activated esters 2,4-dinitrophenyl butanoate (DNPB) and Z-leucine-p-nitrophenyl ester (Z-Leu-PNP). The results showed that the coated GNPs were more active compared to the no-GNP controls, particularly at low $\mathrm{pH}$. This effect was attributed to cooperativity due to confinement on the GNP surface. [125]

Catalysis of DNA nicking was reported by Hsu et al. [127]. The ability of GNPs to confine ligands to locally high concentrations on their surface was again exploited. In this case arylhydrazones were attached to the surface of gold nanoparticles of approximately $13 \mathrm{~nm}$ diameter. These ligands are able to nick DNA upon exposure to UV light $(312 \mathrm{~nm})$ and the nicking activity was enhanced in comparison to the absence of GNP [128] by virtue of the locally high concentration as a result of confinement on the GNP surface.

In another example, hydrolysis of DNA phosphodiester bonds was achieved by attachment of $\mathrm{Zn}$ (II) complexes of BAPA (bis-(2-aminopyridinyl-6-methyl)amine) to an approximately $1.8 \mathrm{~nm}$ diameter GNP surface [129]. Here, the clustering of ligand was able to provide a bimetallic site for cleavage via the activated zinc Lewis acid in conjunction with a hydrogen bond network (Figure 10). This resulted in cleavage of a DNA model substrate (bis-p-nitrophenyl phosphate, BNP) at a rate 100 times that of the ligand when not attached to the GNP. Cleavage of a plasmid DNA substrate was also observed and noticeably this was double strand cleavage resulting in the production of linear DNA products, possibly due to several cleavage reactions occurring simultaneously [129].

Catalysis of peptide-based reactions using has also been demonstrated. Fillon et al. [130] used GNPs functionalized with trimethylammonium, which provided a positively charged surface. Peptides designed with negatively charged residues at appropriate positions bound to the cationic ligand monolayer. Two peptides were used that were two halves of a self-replicating five-heptad alpha helix. These were designed such that one contained a $C$-terminal thioester and the other an $\mathrm{N}$-terminal cysteine so that ligation of the two peptide halves via native chemical ligation [131] could occur. The ligation rate in the presence of GNP was considerably elevated compared to the rate in their absence. The catalytic effect is likely to be due to the charged ligand on the gold, which brings the reactants into close proximity. The peptides were designed so that they were helical only at acidic $\mathrm{pH}$, thus templating and self-replication only occurred at acidic $\mathrm{pH}$. However, addition of GNPs at neutral $\mathrm{pH}$ induced helicity in both the halves and was able to produce ligated product at close to neutral 
$\mathrm{pH}$ [130]. This result may be of interest to researchers in abiogenesis where the potential for the first “initial Darwinian Ancestor" [132] to have been a self-replicating peptide is an intriguing possibility.

Figure 10. $\mathrm{Zn}$ (II) complexes attached to $2 \mathrm{~nm}$ diameter GNPs can form a bimetallic site due to clustering. Such a site is illustrated in the process of cleaving a DNA model substrate bis-p-nitrophenyl phosphate (BNP). Reprinted with permission from Ref. [129]. Copyright (C) 2008 American Chemical Society.

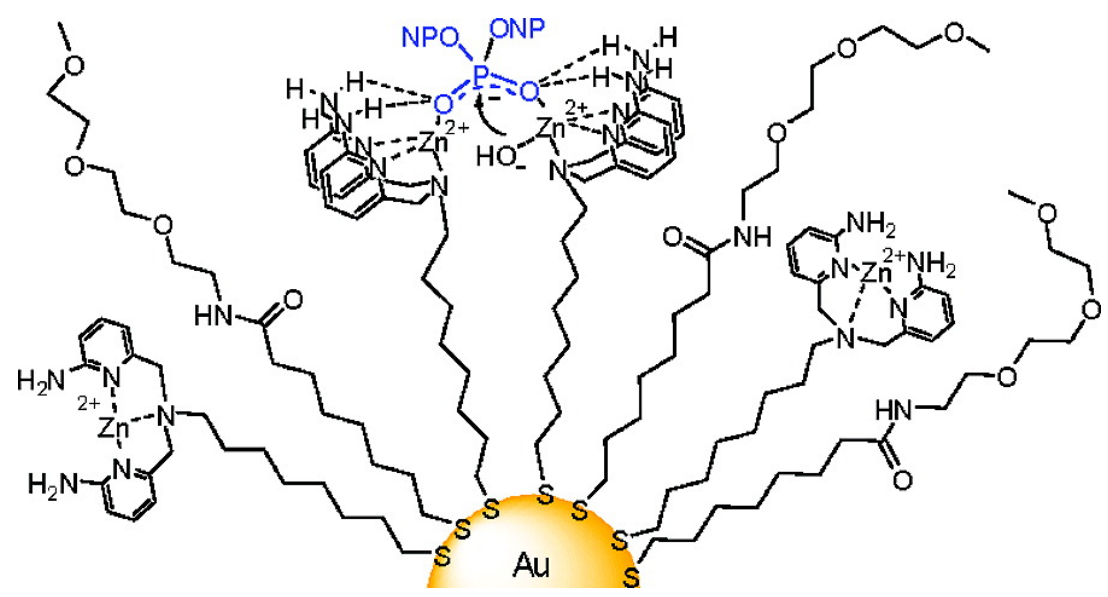

The catalytic properties of liganded GNPs have been utilized in sensors. Bonomi et al. [131] produced such a system. Here the GNP is coated with triazacyclononane-Zn (II), known to catalyze transphophorylation of 2-hydroxypropyl-4-nitrophenylphosphate (HPNPP) [121] as discussed above. This produces p-nitrophenol whose concentration can be monitored by absorbance at $400 \mathrm{~nm}$. This feature was exploited to produce a sensor able to report on the activity of a protease, subtilisin A. An intact oligoanionic peptide substrate was able to bind to the GNP surface due to the presence of the positively charged ligand on the surface. The presence of the peptide on the surface blocked the reaction with HPNPP. However, when the enzyme digested the peptide substrate this binding was abolished and the reaction with HPNPP could occur leading to a change in absorption signal. The system was shown to work for detection of the activity of other enzymes, which changed the negative charges on their substrates.

Nucleic acids are trivial to attach to GNPs and both DNA RNA molecules with enzymatic activities (DNAzymes and ribozymes) are widely known [133,134]. A common application in combination with GNPs is in detectors/sensors. DNA strands of complementary sequence form a double helix so that GNPs coated with such sequences will aggregate, leading to color changes due to plasmonic effects. The inclusion of DNAzymes, which in the presence of a specific cofactor will cleave the DNA, leading to disaggregation, forms the basis of a colorimetric detector for the cofactor in question. In one such case the DNA strands were partially complimentary and linked GNPs together into aggregates, which were blue in color and also included a DNAzyme. In the presence of $\mathrm{UO}_{2}{ }^{2+}$ the DNAzyme cleaved the connecting strands, resulting in disaggregation of the GNPs and a change in color to red, resulting in a simple uranyl sensor [135]. The concept of DNAzyme attached to a GNP surface has been applied on a number of occasions (see Liu and $\mathrm{Lu}$ [136] for a review).

In a reversal of the above technique, Zhao et al. demonstrated a DNAzyme-coated GNP, which caused aggregation of the GNPs in the presence of cofactor [137]. In these experiments, GNPs were 
modified by the attachment of a surface ligand which consisted of one DNA strand (with a single RNA linkage) and a partially complimentary strand of DNA containing the "8-17" DNAzyme [138]. This DNAzyme can cleave DNA containing a single RNA linkage when $\mathrm{Pb}^{2+}$ is present $[139,140]$. The presence of the DNA ligand on the GNPs stabilizes them against aggregation even at relatively high salt concentrations due to the length and negative charge of the DNA. In the presence of the $\mathrm{Pb}^{2+}$ cofactor, the DNAzyme cleaves the ligand removing its stabilizing effect. The gold particles then aggregate leading to a red-to-purple color change over 10 minutes at room temperature.

Enzymes can also be attached to the GNP: Brennan et al. were able to connect lipase from Thermomyces lanuginosus to $\sim 14 \mathrm{~nm}$ diameter GNPs [141]. In this case the surface of the GNP was functionalized by the attachment of a thiolate containing azide-terminated ligand. The $30 \mathrm{kDa}$ enzyme was modified to add a single accessible lysine residue which was subsequently modified to provide an acetylene group for utilization in a click chemistry reaction for attachment to the GNP. A lipase activity test confirmed that the attached lipase was active.

Even when the reaction is in fact catalyzed by the gold, the ligand can still play an important role as it may limit access of the reactants to the gold surface, as has been shown for example in tests of the ability of GNPs coated with different ligands to catalyze the aerobic oxidation of glycerol [142,143] where a larger ligand (PVA) was found to result in decreased catalytic activity compared to a smaller ligand (THPC; tetrakishhydroxypropylphosphonium).

\section{Conclusions and Future Potential}

GNPs have a long history of medicinal use and a more recently as catalysts. The fusion of these two fields into one where GNPs is used to catalyze reactions involving biological molecules is a promising possibility. Potential avenues include the use of GNPs to replace biological molecules in catalytic reactions where longer-lasting, more robust systems are required. A second possibility is using GNPs to react with biological molecules to produce new structures, which may have applications in bionanoscience. If the latter proves to be a catalytic effect that can be controlled then bespoke modification of protein structure could be possible. The interaction of GNPs with biological molecules is complex and the field remains open to many important potential discoveries.

\section{Acknowledgments}

The author thanks Ali Malay and Mathias Brust for critical reading of the manuscript and Joanne Yu for Figure 2. JGH was funded by RIKEN.

\section{Conflicts of Interest}

The author declares no conflict of interest.

\section{References}

1. Faraday, M. The Bakerian lecture: experimental relations of gold (and other metals) to light. Philos. Trans. R. Soc. London 1857, 147, 145-181. 
2. Edwards, P.P.; Thomas, J.M. Gold in a metallic divided state-From Faraday to present-day nanoscience. Angew. Chem. Int. Ed. 2007, 46, 5480-5486.

3. Tweney, R.D. Discovering discovery: how Faraday found the first metallic colloid. Perspect. Sci. 2006, 14, 97-121.

4. Haruta, M.; Kobayashi, T.; Sano, H.; Yamada, N. Novel gold catalysts for the oxidation of carbon monoxide at a temperature far below $0{ }^{\circ} \mathrm{C}$. Chem. Lett. 1987, 16, 405-408.

5. Turkevich, J.; Stevenson, P.C.; Hillier, J. A study of the nucleation and growth processes in the synthesis of colloidal gold. Discuss. Faraday Soc. 1951, 11, 55-75.

6. Enustun, B.V.; Turkevich, J. Coagulation of colloidal gold. J. Am. Chem. Soc. 1963, 85, 3317-3328.

7. Turkevich, J. Colloidal gold. Part I. Gold Bull. 1985, 18, 86-91.

8. $\quad$ Brust, M.; Walker, M.; Bethell, D.; Schiffrin, D.J.; Whyman, R. Synthesis of thiol-derivatised gold nanoparticles in a two-phase Liquid-Liquid system. J. Chem. Soc. Chem. Commun. 1994, 801-802.

9. Grzelczak, M.; Perez-Juste, J.; Mulvaney, P.; Liz-Marzan, L.M. Shape control in gold nanoparticle synthesis. Chem. Soc. Rev. 2008, 37, 1783-1791.

10. Pan, Y.; Neuss, S.; Leifert, A.; Fischler, M.; Wen, F.; Simon, U.; Schmid, G.; Brandau, W.; Jahnen-Dechent, W. Size-dependent cytotoxicity of gold nanoparticles. Small 2007, 3, 1941-1949.

11. Pan, Y.; Leifert, A.; Ruau, D.; Neuss, S.; Bornemann, J.; Schmid, G.; Brandau, W.; Simon, U.; Jahnen-Dechent, W. Gold nanoparticles of diameter $1.4 \mathrm{~nm}$ trigger necrosis by oxidative stress and mitochondrial damage. Small 2009, 5, 2067-2076.

12. Hoa, X.D.; Kirk, A.G.; Tabrizian, M. Towards integrated and sensitive surface plasmon resonance biosensors: A review of recent progress. Biosens. Bioelectron. 2007, 23, 151-160.

13. Liedberg, B.; Nylander, C.; Lunström, I. Surface plasmon resonance for gas detection and biosensing. Sens. Actuators 1983, 4, 299-304.

14. Murphy, C.J.; Gole, A.M.; Stone, J.W.; Sisco, P.N.; Alkilany, A.M.; Goldsmith, E.C.; Baxter, S.C. Gold nanoparticles in biology: beyond toxicity to cellular imaging. Acc. Chem. Res. 2008, 41, 1721-1730.

15. Kelly, K.L.; Coronado, E.; Zhao, L.L.; Schatz, G.C. The Optical Properties of metal nanoparticles: The influence of size, shape, and dielectric environment. J. Phys. Chem. B 2002, 107, 668-677.

16. Dusemund, B.; Hoffmann, A.; Salzmann, T.; Kreibig, U.; Schmid, G. Cluster matter: The transition of optical elastic scattering to regular reflection. Z. Phys. D 1991, 20, 305-308.

17. Katz, E.; Willner, I. Integrated nanoparticle-biomolecule hybrid systems: Synthesis, properties, and applications. Angew. Chem. Int. Ed. 2004, 43, 6042-6108.

18. Saha, K.; Agasti, S.S.; Kim, C.; Li, X.; Rotello, V.M. Gold nanoparticles in chemical and biological sensing. Chem. Rev. 2012, 112, 2739-2779.

19. Stockman, M.I. Nanoplasmonics: Past, present, and glimpse into future. Opt. Express. 2011, 19, 22029-22106.

20. Tanaka, R.; Yuhi, T.; Nagatani, N.; Endo, T.; Kerman, K.; Takamura, Y.; Tamiya, E. A novel enhancement assay for immunochromatographic test strips using gold nanoparticles. Anal. Bioanal. Chem. 2006, 385, 1414-1420. 
21. Cole, J.R.; Mirin, N.A.; Knight, M.W.; Goodrich, G.P.; Halas, N.J. Photothermal efficiencies of nanoshells and nanorods for clinical therapeutic applications. J. Phys. Chem. C 2009, 113, 12090-12094.

22. Jain, P.K.; Lee, K.S.; El-Sayed, I.H.; El-Sayed, M.A. Calculated absorption and scattering properties of gold nanoparticles of different size, shape, and composition: applications in biological imaging and biomedicine. J. Phys. Chem. B 2006, 110, 7238-7248.

23. Loo, C.; Lin, A.; Hirsch, L.; Lee, M.H.; Barton, J.; Halas, N.; West, J.; Drezek, R. Nanoshell-enabled photonics-based imaging and therapy of cancer. Technol. Cancer Res. Treat. 2004, 3, 33-40.

24. O'Neal, D.P.; Hirsch, L.R.; Halas, N.J.; Payne, J.D.; West, J.L. Photo-thermal tumor ablation in mice using near infrared-absorbing nanoparticles. Cancer Lett. 2004, 209, 171-176.

25. Hirsch, L.R.; Stafford, R.J.; Bankson, J.A.; Sershen, S.R.; Rivera, B.; Price, R.E.; Hazle, J.D.; Halas, N.J.; West, J.L. Nanoshell-mediated near-infrared thermal therapy of tumors under magnetic resonance guidance. Proc. Natl. Acad. Sci. USA 2003, 100, 13549-13554.

26. Cardinal, J.; Klune, J.R.; Chory, E.; Jeyabalan, G.; Kanzius, J.S.; Nalesnik, M.; Geller, D.A. Noninvasive radiofrequency ablation of cancer targeted by gold nanoparticles. Surgery 2008, 144, 125-132.

27. Pissuwan, D.; Valenzuela, S.M.; Cortie, M.B. Therapeutic possibilities of plasmonically heated gold nanoparticles. Trends Biotechnol. 2006, 24, 62-67.

28. Haynes, C.L.; McFarland, A.D.; Duyne, R.P.V. Surface-enhanced raman spectroscopy. Anal. Chem. 2005, 77, 338 A-346 A.

29. Watson, J.D.; Crick, F.H. Molecular structure of nucleic acids; A structure for deoxyribose nucleic acid. Nature 1953, 171, 737-738.

30. Alivisatos, A.; Johnsson, K.; Peng, X.; Wilson, T.; Loweth, C.; Bruchez, M.; Schultz, P. Organization of 'nanocrystal molecules' using DNA. Nature 1996, 382, 609-611.

31. Pinto, Y.Y.; Le, J.D.; Seeman, N.C.; Musier-Forsyth, K.; Taton, T.A.; Kiehl, R.A. Sequence-encoded self-assembly of multiple-nanocomponent arrays by 2D DNA scaffolding. Nano Lett. 2005, 5, 2399-2402.

32. Zheng, J.; Constantinou, P.E.; Micheel, C.; Alivisatos, A.P.; Kiehl, R.A.; Seeman, N.C. Two-dimensional nanoparticle arrays show the organizational power of robust DNA motifs. Nano Lett. 2006, 6, 1502-1504.

33. Sharma, J.; Chhabra, R.; Liu, Y.; Ke, Y.; Yan, H. DNA-templated self-assembly of twodimensional and periodical gold nanoparticle arrays. Angew. Chem. Int. Ed. 2006, 45, 730-735.

34. Lee, J.H.; Wernette, D.P.; Yigit, M.V.; Liu, J.; Wang, Z.; Lu, Y. Site-specific control of distances between gold nanoparticles using phosphorothioate anchors on DNA and a short bifunctional molecular fastener. Angew. Chem. Int. Ed. 2007, 46, 9006-9010.

35. Ludueña, R.F.; Roach, M.C.; Trcka, P.P.; Weintraub, S. $N, N$-Bis( $\alpha$-iodoacetyl)-2,2'dithiobis(ethylamine), a reversible crosslinking reagent for protein sulfhydryl groups. Anal. Biochem. 1981, 117, 76-80.

36. Ozbay, E. Plasmonics: Merging photonics and electronics at nanoscale dimensions. Science 2006, 311, 189-193.

37. Liu, Z.; Searson, P.C. Single nanoporous gold nanowire sensors. J. Phys. Chem. B 2006, 110, $4318-4322$. 
38. Chirea, M.; Freitas, A.; Vasile, B.S.; Ghitulica, C.; Pereira, C.M.; Silva, F. Gold nanowire networks: Synthesis, characterization, and catalytic activity. Langmuir 2011, 27, 3906-3913.

39. Bai, X.; Gao, Y.; Liu, H.-g.; Zheng, L. Synthesis of amphiphilic ionic liquids terminated gold nanorods and their superior catalytic activity for the reduction of nitro compounds. $J$. Phys. Chem. C 2009, 113, 17730-17736.

40. Richter, J. Metallization of DNA. Physica E 2003, 16, 157-173.

41. Ongaro, A.; Griffin, F.; Beecher, P.; Nagle, L.; Iacopino, D.; Quinn, A.; Redmond, G.; Fitzmaurice, D. DNA-Templated Assembly of Conducting Gold Nanowires between Gold Electrodes on a Silicon Oxide Substrate. Chem. Mater. 2005, 17, 1959-1964.

42. Kim, H.J.; Roh, Y.; Hong, B. Selective Formation of a Latticed Nanostructure with the Precise Alignment of DNA-Templated Gold Nanowires. Langmuir 2010, 26, 18315-18319.

43. Harnack, O.; Ford, W.E.; Yasuda, A.; Wessels, J.M. Tris(hydroxymethyl)phosphine-Capped Gold Particles Templated by DNA as Nanowire Precursors. Nano Lett. 2002, 2, 919-923.

44. Yonezawa, T.; Onoue, S.-y.; Kimizuka, N. Metal Coating of DNA Molecules by Cationic, Metastable Gold Nanoparticles. Chem. Lett. 2002, 31, 1172-1173.

45. Patolsky, F.; Weizmann, Y.; Lioubashevski, O.; Willner, I. Au-Nanoparticle Nanowires Based on DNA and Polylysine Templates. Angew. Chem. Int. Ed. 2002, 41, 2323-2327.

46. Haruta, M. Catalysis of Gold Nanoparticles Deposited on Metal Oxides. CATTECH 2002, 6, $102-115$.

47. Fu, T.J.; Seeman, N.C. DNA double-crossover molecules. Biochemistry 1993, 32, 3211-3220.

48. Ding, B.; Sha, R.; Seeman, N.C. Pseudohexagonal 2D DNA Crystals from Double Crossover Cohesion. J. Am. Chem. Soc. 2004, 126, 10230-10231.

49. Le, J.D.; Pinto, Y.; Seeman, N.C.; Musier-Forsyth, K.; Taton, T.A.; Kiehl, R.A. DNA-Templated Self-Assembly of Metallic Nanocomponent Arrays on a Surface. Nano Lett. 2004, 4, 2343-2347.

50. Mastroianni, A.J.; Claridge, S.A.; Alivisatos, A.P. Pyramidal and Chiral Groupings of Gold Nanocrystals Assembled Using DNA Scaffolds. J. Am. Chem. Soc. 2009, 131, 8455-8459.

51. Chen, J.H.; Seeman, N.C. Synthesis from DNA of a molecule with the connectivity of a cube. Nature 1991, 350, 631-633.

52. Erben, C.M.; Goodman, R.P.; Turberfield, A.J. A Self-Assembled DNA Bipyramid. J. Am. Chem. Soc. 2007, 129, 6992-6993.

53. Zhang, Y.; Seeman, N.C. Construction of a DNA-Truncated Octahedron. J. Am. Chem. Soc. 1994, 116, 1661-1669.

54. Rothemund, P.W. Folding DNA to create nanoscale shapes and patterns. Nature 2006, 440, 297-302.

55. Andersen, E.S.; Dong, M.; Nielsen, M.M.; Jahn, K.; Subramani, R.; Mamdouh, W.; Golas, M.M.; Sander, B.; Stark, H.; Oliveira, C.L.; et al. Self-assembly of a nanoscale DNA box with a controllable lid. Nature 2009, 459, 73-76.

56. Kuzuya, A.; Komiyama, M. Design and construction of a box-shaped 3D-DNA origami. Chem. Commun. 2009, 4182-4184.

57. Kuzyk, A.; Schreiber, R.; Fan, Z.; Pardatscher, G.; Roller, E.-M.; Hogele, A.; Simmel, F.C.; Govorov, A.O.; Liedl, T. DNA-based self-assembly of chiral plasmonic nanostructures with tailored optical response. Nature 2012, 483, 311-314. 
58. Yang, C.; Manocchi, A.K.; Lee, B.; Yi, H. Viral templated palladium nanocatalysts for dichromate reduction. Appl. Catal. B 2010, 93, 282-291.

59. Nam, Y.S.; Magyar, A.P.; Lee, D.; Kim, J.-W.; Yun, D.S.; Park, H.; Pollom, T.S.; Weitz, D.A.; Belcher, A.M. Biologically templated photocatalytic nanostructures for sustained light-driven water oxidation. Nat. Nanotechnol. 2010, 5, 340-344.

60. Scheibel, T.; Parthasarathy, R.; Sawicki, G.; Lin, X.-M.; Jaeger, H.; Lindquist, S.L. Conducting nanowires built by controlled self-assembly of amyloid fibers and selective metal deposition. Proc. Natl. Acad. Sci. USA 2003, 100, 4527-4532.

61. Glover, J.R.; Kowal, A.S.; Schirmer, E.C.; Patino, M.M.; Liu, J.J.; Lindquist, S. Self-seeded fibers formed by Sup35, the protein determinant of [PSI+], a heritable prion-like factor of $S$. cerevisiae. Cell 1997, 89, 811-819.

62. Steinmetz, N.F.; Evans, D.J. Utilisation of plant viruses in bionanotechnology. Org. Biomol. Chem. 2007, 5, 2891-2902.

63. Lin, T.; Chen, Z.; Usha, R.; Stauffacher, C.V.; Dai, J.B.; Schmidt, T.; Johnson, J.E. The refined crystal structure of cowpea mosaic virus at 2.8 A resolution. Virology 1999, 265, 20-34.

64. Steinmetz, N.F.; Lomonossoff, G.P.; Evans, D.J. Cowpea Mosaic Virus for Material Fabrication: Addressable Carboxylate Groups on a Programmable Nanoscaffold. Langmuir 2006, 22, 3488-3490.

65. Steinmetz, N.F.; Lomonossoff, G.P.; Evans, D.J. Decoration of Cowpea Mosaic Virus with Multiple, Redox-Active, Organometallic Complexes. Small 2006, 2, 530-533.

66. Blum, A.S.; Soto, C.M.; Wilson, C.D.; Cole, J.D.; Kim, M.; Gnade, B.; Chatterji, A.; Ochoa, W.F.; Lin, T.; Johnson, J.E.; et al. Cowpea Mosaic Virus as a Scaffold for 3-D Patterning of Gold Nanoparticles. Nano Lett. 2004, 4, 867-870.

67. Zafeiratos, S.; Piccinin, S.; Teschner, D. Alloys in catalysis: Phase separation and surface segregation phenomena in response to the reactive environment. Catal. Sci. Technol. 2012, 2, 1787-1801.

68. Evans, D.J. The bionanoscience of plant viruses: templates and synthons for new materials. J. Mater. Chem. 2008, 18, 3746-3754.

69. Shenton, W.; Douglas, T.; Young, M.; Stubbs, G.; Mann, S. Inorganic-Organic Nanotube Composites from Template Mineralization of Tobacco Mosaic Virus. Adv. Mater. 1999, 11, 253-256.

70. Knez, M.; Kadri, A.; Wege, C.; Gösele, U.; Jeske, H.; Nielsch, K. Atomic Layer Deposition on Biological Macromolecules: Metal Oxide Coating of Tobacco Mosaic Virus and Ferritin. Nano Lett. 2006, 6, 1172-1177.

71. Dujardin, E.; Peet, C.; Stubbs, G.; Culver, J.N.; Mann, S. Organization of Metallic Nanoparticles Using Tobacco Mosaic Virus Templates. Nano Lett. 2003, 3, 413-417.

72. Lee, S.-Y.; Royston, E.; Culver, J.N.; Harris, M.T. Improved metal cluster deposition on a genetically engineered tobacco mosaic virus template. Nanotechnology 2005, 16, S435.

73. Lim, J.-S.; Kim, S.-M.; Lee, S.-Y.; Stach, E.A.; Culver, J.N.; Harris, M.T. Formation of Au/Pd Alloy Nanoparticles on TMV. J. Nanomater. 2010, 2010, doi:10.1155/2010/620505.

74. Khan, A.A.; Fox, E.K.; Gorzny, M.L.; Nikulina, E.; Brougham, D.F.; Wege, C.; Bittner, A.M. $\mathrm{pH}$ control of the electrostatic binding of gold and iron oxide nanoparticles to tobacco mosaic virus. Langmuir 2013, 29, 2094-2098. 
75. Guli, M.; Lambert, E.M.; Li, M.; Mann, S. Template-directed synthesis of nanoplasmonic arrays by intracrystalline metalization of cross-linked lysozyme crystals. Angew. Chem. Int. Ed. 2010, 49, 520-523.

76. Wei, H.; Wang, Z.; Zhang, J.; House, S.; Gao, Y.G.; Yang, L.; Robinson, H.; Tan, L.H.; Xing, H.; Hou, C.; et al. Time-dependent, protein-directed growth of gold nanoparticles within a single crystal of lysozyme. Nat. Nanotechnol. 2011, 6, 93-97.

77. Wei, H.; Lu, Y. Catalysis of gold nanoparticles within lysozyme single crystals. Chem. Asian J. 2012, 7, 680-683.

78. McMillan, R.A.; Paavola, C.D.; Howard, J.; Chan, S.L.; Zaluzec, N.J.; Trent, J.D. Ordered nanoparticle arrays formed on engineered chaperonin protein templates. Nat. Mater. 2002, 1, $247-252$.

79. Trent, J.D.; Kagawa, H.K.; Yaoi, T.; Olle, E.; Zaluzec, N.J. Chaperonin filaments: the archaeal cytoskeleton? Proc. Natl. Acad. Sci. USA 1997, 94, 5383-5388.

80. Ellis, M.J.; Knapp, S.; Koeck, P.J.B.; Fakoor-Biniaz, Z.; Ladenstein, R.; Hebert, H. Two-Dimensional Crystallization of the Chaperonin TF55 from the Hyperthermophilic ArchaeonSulfolobus solfataricus. J. Struct. Biol. 1998, 123, 30-36.

81. Bond, G.C., Louis, C.; Thompson, D.T. Catalysis by Gold; Imperial College Press: London, UK, 2006; Volume 6.

82. Hashmi, A.S.; Hutchings, G.J. Gold catalysis. Angew. Chem. Int. Ed. 2006, 45, 7896-7936.

83. Della Pina, C.; Falletta, E.; Rossi, M. Update on selective oxidation using gold. Chem. Soc. Rev. 2012, 41, 350-369.

84. Mills, G.; Gordon, M.S.; Metiu, H. Oxygen adsorption on Au clusters and a rough Au(111) surface: The role of surface flatness, electron confinement, excess electrons, and band gap. $J$. Chem. Phys. 2003, 118, 4198-4205.

85. Bond, G.C.; Thompson, D.T. Catalysis by Gold. Cataly. Rev. 1999, 41, 319-388.

86. Wales, D.J. Structure, Dynamics, and Thermodynamics of Clusters: Tales from Topographic Potential Surfaces. Science 1996, 271, 925-929.

87. Boyen, H.G.; Kastle, G.; Weigl, F.; Koslowski, B.; Dietrich, C.; Ziemann, P.; Spatz, J.P.; Riethmuller, S.; Hartmann, C.; Moller, M.; et al. Oxidation-resistant gold-55 clusters. Science 2002, 297, 1533-1536.

88. Bond, G.C.; Thompson, D.T. Gold-catalysed oxidation of carbon monoxide. Gold Bull. 2000, 33, 41-50.

89. Benkovic, S.J.; Hammes-Schiffer, S., A perspective on enzyme catalysis. Science 2003, 301, 1196-1202.

90. Comotti, M.; Della Pina, C.; Matarrese, R.; Rossi, M. The catalytic activity of "naked" gold particles. Angew. Chem. Int. Ed. 2004, 43, 5812-5815.

91. Boronat, M.; Corma, A. Oxygen activation on gold nanoparticles: Separating the influence of particle size, particle shape and support interaction. Dalton Trans. 2010, 39, 8538-8546.

92. Kotov, N.A. Inorganic Nanoparticles as Protein Mimics. Science 2010, 330, 188-189.

93. Witt, S.; Wohlfahrt, G.; Schomburg, D.; Hecht, H.J.; Kalisz, H.M. Conserved arginine-516 of Penicillium amagasakiense glucose oxidase is essential for the efficient binding of beta-Dglucose. Biochem. J. 2000, 347, 553-559. 
94. Wild, S.; Roglic, G.; Green, A.; Sicree, R.; King, H. Global Prevalence of Diabetes: Estimates for the year 2000 and projections for 2030. Diabetes Care 2004, 27, 1047-1053.

95. Zheng, X.; Liu, Q.; Jing, C.; Li, Y.; Li, D.; Luo, W.; Wen, Y.; He, Y.; Huang, Q.; Long, Y.T.; et al. Catalytic gold nanoparticles for nanoplasmonic detection of DNA hybridization. Angew. Chem. Int. Ed. 2011, 50, 11994-11998.

96. Newman, J.D.; Turner, A.P.F. Home blood glucose biosensors: A commercial perspective. Biosens. Bioelectron. 2005, 20, 2435-2453.

97. Beltrame, P.; Comotti, M.; Della Pina, C.; Rossi, M. Aerobic oxidation of glucose: II. Catalysis by colloidal gold. Appl. Catal. A 2006, 297, 1-7.

98. Biella, S.; Prati, L.; Rossi, M. Selective Oxidation of D-Glucose on Gold Catalyst. J. Catal. 2002, 206, 242-247.

99. Luo, W.; Zhu, C.; Su, S.; Li, D.; He, Y.; Huang, Q.; Fan, C. Self-Catalyzed, Self-Limiting Growth of Glucose Oxidase-Mimicking Gold Nanoparticles. ACS Nano 2010, 4, 7451-7458.

100. Li, H.; Rothberg, L. Colorimetric detection of DNA sequences based on electrostatic interactions with unmodified gold nanoparticles. Proc. Natl. Acad. Sci. USA 2004, 101, 14036-14039.

101. Li, H.; Rothberg, L.J. Label-Free Colorimetric Detection of Specific Sequences in Genomic DNA Amplified by the Polymerase Chain Reaction. J. Am. Chem. Soc. 2004, 126, 10958-10961.

102. Cedervall, T.; Lynch, I.; Lindman, S.; Berggard, T.; Thulin, E.; Nilsson, H.; Dawson, K.; Linse, S. Understanding the nanoparticle-protein corona using methods to quntify exchange rates and affinities of proteins for nanoparticles. Proc. Natl. Acad. Sci. USA 2007, 104, 2050-2055.

103. Lacerda, S.H.D.P.; Park, J.J.; Meuse, C.; Pristinski, D.; Becker, M.L.; Karim, A.; Douglas, J.F. Interaction of Gold Nanoparticles with Common Human Blood Proteins. ACS Nano 2009, 4, 365-379.

104. Rocker, C.; Potzl, M.; Zhang, F.; Parak, W.J.; Nienhaus, G.U. A quantitative fluorescence study of protein monolayer formation on colloidal nanoparticles. Nat. Nanotechnol. 2009, 4, 577-580.

105. Babitzke, P.; Gollnick, P. Posttranscription initiation control of tryptophan metabolism in Bacillus subtilis by the trp RNA-binding attenuation protein (TRAP), anti-TRAP, and RNA structure. J. Bacteriol. 2001, 183, 5795-5802.

106. Chen, X.; Antson, A.A.; Yang, M.; Li, P.; Baumann, C.; Dodson, E.J.; Dodson, G.G.; Gollnick, P. Regulatory features of the trp operon and the crystal structure of the trp RNA-binding attenuation protein from Bacillus stearothermophilus. J. Mol. Biol. 1999, 289, 1003-1016.

107. Antson, A.A.; Otridge, J.; Brzozowski, A.M.; Dodson, E.J.; Dodson, G.G.; Wilson, K.S.; Smith, T.M.; Yang, M.; Kurecki, T.; Gollnick, P. The structure of trp RNA-binding attenuation protein. Nature 1995, 374, 693-700.

108. Heddle, J.G.; Okajima, T.; Scott, D.J.; Akashi, S.; Park, S.Y.; Tame, J.R. Dynamic allostery in the ring protein TRAP. J. Mol. Biol. 2007, 371, 154-167.

109. Heddle, J.G.; Yokoyama, T.; Yamashita, I.; Park, S.Y.; Tame, J.R. Rounding up: Engineering 12-membered rings from the cyclic 11-mer TRAP. Structure 2006, 14, 925-933.

110. Heddle, J.G.; Fujiwara, I.; Yamadaki, H.; Yoshii, S.; Nishio, K.; Addy, C.; Yamashita, I.; Tame, J.R. Using the ring-shaped protein TRAP to capture and confine gold nanodots on a surface. Small 2007, 3, 1950-1956. 
111. Miranda, F.F.; Iwasaki, K.; Akashi, S.; Sumitomo, K.; Kobayashi, M.; Yamashita, I.; Tame, J.R.H.; Heddle, J.G. A Self-Assembled Protein Nanotube with High Aspect Ratio. Small 2009, 5, 2077-2084.

112. Malay, A.D.; Heddle, J.G.; Tomita, S.; Iwasaki, K.; Miyazaki, N.; Sumitomo, K.; Yanagi, H.; Yamashita, I.; Uraoka, Y. Gold Nanoparticle-Induced Formation of Artificial Protein Capsids. Nano Lett. 2012, 12, 2056-2059.

113. Wittstock, A.; Zielasek, V.; Biener, J.; Friend, C.M.; Baumer, M. Nanoporous gold catalysts for selective gas-phase oxidative coupling of methanol at low temperature. Science 2010, 327, 319-322.

114. Hakkinen, H. The gold-sulfur interface at the nanoscale. Nat. Chem. 2012, 4, 443-455.

115. Zhang, D.; Neumann, O.; Wang, H.; Yuwono, V.M.; Barhoumi, A.; Perham, M.; Hartgerink, J.D.; Wittung-Stafshede, P.; Halas, N.J. Gold Nanoparticles Can Induce the Formation of Proteinbased Aggregates at Physiological pH. Nano Lett. 2009, 9, 666-671.

116. Aubin-Tam, M.E.; Hamad-Schifferli, K. Structure and function of nanoparticle-protein conjugates. Biomed. Mater. 2008, 3, 034001.

117. Treuel, L.; Malissek, M.; Gebauer, J.S.; Zellner, R. The Influence of Surface Composition of Nanoparticles on their Interactions with Serum Albumin. ChemPhysChem 2010, 11, 3093-3099.

118. Lynch, I.; Dawson, K.A. Protein-nanoparticle interactions. Nano Today 2008, 3, 40-47.

119. Mancin, F.; Prins, L.J.; Scrimin, P. Catalysis on gold-nanoparticle-passivating monolayers. Curr. Opin. Colloid Interface Sci. 2013, 18, 61-69.

120. Mikami, Y.; Dhakshinamoorthy, A.; Alvaro, M.; Garcia, H. Catalytic activity of unsupported gold nanoparticles. Cataly. Sci. Technol. 2013, 3, 58-69.

121. Manea, F.; Houillon, F.B.; Pasquato, L.; Scrimin, P. Nanozymes: Gold-Nanoparticle-Based Transphosphorylation Catalysts. Angew. Chem. Int. Ed. 2004, 43, 6165-6169.

122. Pingoud, A.; Fuxreiter, M.; Pingoud, V.; Wende, W. Type II restriction endonucleases: Structure and mechanism. Cell. Mol. Life Sci. 2005, 62, 685-707.

123. Pommier, Y.; Leo, E.; Zhang, H.; Marchand, C. DNA Topoisomerases and Their Poisoning by Anticancer and Antibacterial Drugs. Chem. Biol. 2010, 17, 421-433.

124. Zaupa, G.; Mora, C.; Bonomi, R.; Prins, L.J.; Scrimin, P. Catalytic self-assembled monolayers on Au nanoparticles: The source of catalysis of a transphosphorylation reaction. Chemistry A 2011, 17, 4879-4889.

125. Pengo, P.; Polizzi, S.; Pasquato, L.; Scrimin, P. Carboxylate-imidazole cooperativity in dipeptide-functionalized gold nanoparticles with esterase-like activity. J. Am. Chem. Soc. 2005, 127, 1616-1617.

126. Northrop, D.B. Follow the Protons: A Low-Barrier Hydrogen Bond Unifies the Mechanisms of the Aspartic Proteases. Acc. Chem. Res. 2001, 34, 790-797.

127. Hsu, M.H.; Josephrajan, T.; Yeh, C.S.; Shieh, D.B.; Su, W.C.; Hwu, J.R. Novel arylhydrazoneconjugated gold nanoparticles with DNA-cleaving ability: The first DNA-nicking nanomaterial. Bioconj. Chem. 2007, 18, 1709-1712.

128. Hwu, J.R.; Chieh Lin, C.; Hsien Chuang, S.; Yung King, K.; Su, T.-R.; Tsay, S.-C. Aminyl and iminyl radicals from arylhydrazones in the photo-induced DNA cleavage. Bioorg. Med. Chem. 2004, 12, 2509-2515. 
129. Bonomi, R.; Selvestrel, F.; Lombardo, V.; Sissi, C.; Polizzi, S.; Mancin, F.; Tonellato, U.; Scrimin, P. Phosphate diester and DNA hydrolysis by a multivalent, nanoparticle-based catalyst. J. Am. Chem. Soc. 2008, 130, 15744-15745.

130. Fillon, Y.; Verma, A.; Ghosh, P.; Ernenwein, D.; Rotello, V.M.; Chmielewski, J. Peptide ligation catalyzed by functionalized gold nanoparticles. J. Am. Chem. Soc. 2007, 129, 6676-6677.

131. Dawson, P.; Muir, T.; Clark-Lewis, I.; Kent, S. Synthesis of proteins by native chemical ligation. Science 1994, 266, 776-779.

132. Yarus, M. Getting past the RNA world: The initial Darwinian ancestor. Cold Spring Harb. Perspect. Biol. 2011, doi:10.1101/cshperspect.a003590.

133. Silverman, S.K., Deoxyribozymes: DNA catalysts for bioorganic chemistry. Org. Biomol. Chem. 2004, 2, 2701-2706.

134. Fiammengo, R., Jäschke, A. Nucleic acid enzymes. Curr. Opin. Biotech. 2005, 16, 614-621..

135. Lee, J.H.; Wang, Z.; Liu, J.; Lu, Y. Highly sensitive and selective colorimetric sensors for uranyl (UO2(2+)): Development and comparison of labeled and label-free DNAzyme-gold nanoparticle systems. J. Am. Chem. Soc. 2008, 130, 14217-14226.

136. Lu, Y.; Liu, J. Functional DNA nanotechnology: Emerging applications of DNAzymes and aptamers. Curr. Opin. Biotech. 2006, 17, 580-588.

137. Zhao, W.; Lam, J.C.; Chiuman, W.; Brook, M.A.; Li, Y. Enzymatic cleavage of nucleic acids on gold nanoparticles: A generic platform for facile colorimetric biosensors. Small 2008, 4, 810-816.

138. Santoro, S.W.; Joyce, G.F. A general purpose RNA-cleaving DNA enzyme. Proc. Natl. Acad. Sci. USA 1997, 94, 4262-4266.

139. Li, J.; Lu, Y. A Highly Sensitive and Selective Catalytic DNA Biosensor for Lead Ions. J. Am. Chem. Soc. 2000, 122, 10466-10467.

140. Liu, J.; Lu, Y. A Colorimetric Lead Biosensor Using DNAzyme-Directed Assembly of Gold Nanoparticles. J. Am. Chem. Soc. 2003, 125, 6642-6643.

141. Brennan, J.L.; Hatzakis, N.S.; Tshikhudo, T.R.; Dirvianskyte, N.; Razumas, V.; Patkar, S.; Vind, J.; Svendsen, A.; Nolte, R.J.; Rowan, A.E.; et al. Bionanoconjugation via click chemistry: The creation of functional hybrids of lipases and gold nanoparticles. Bioconj. Chem. 2006, 17, 1373-1375.

142. Prati, L.; Spontoni, P.; Gaiassi, A. From Renewable to Fine Chemicals Through Selective Oxidation: The Case of Glycerol. Top. Catal. 2009, 52, 288-296.

143. Villa, A.; Wang, D.; Su, D.S.; Prati, L. Gold Sols as Catalysts for Glycerol Oxidation: The Role of Stabilizer. ChemCatChem 2009, 1, 510-514.

(C) 2013 by the authors; licensee MDPI, Basel, Switzerland. This article is an open access article distributed under the terms and conditions of the Creative Commons Attribution license (http://creativecommons.org/licenses/by/3.0/). 